\title{
Expression of phosphodiesterase 6 (PDE6) in human breast cancer cells
}

\author{
Hongli Dong ${ }^{1}$, Kevin P Claffey ${ }^{1}$, Stefan Brocke ${ }^{2}$ and Paul M Epstein ${ }^{1 *}$
}

\begin{abstract}
Considerable epidemiological evidence demonstrates a positive association between artificial light at night (LAN) levels and incidence rates of breast cancer, suggesting that exposure to LAN is a risk factor for breast cancer. There is a 30-50\% higher risk of breast cancer in the highest LAN exposed countries compared to the lowest LAN countries, and studies showing higher incidence of breast cancer among shift workers exposed to more LAN have led the International Agency for Research on Cancer to classify shift work as a probable human carcinogen. Nevertheless, the means by which light can affect breast cancer is still unknown. In this study we examined established human breast cancer cell lines and patients' primary breast cancer tissues for expression of genetic components of phosphodiesterase 6 (PDE6), a CGMP-specific PDE involved in transduction of the light signal, and previously thought to be selectively expressed in photoreceptors. By microarray analysis we find highly significant expression of mRNA for the PDE6B, PDE6C, and PDE6D genes in both the cell lines and patients' tissues, minimal expression of PDE6A and PDE6G and no expression of PDE6H. Using antibody specific for PDE6 $\beta$, we find expression of PDE6B protein in a wide range of patients' tissues by immunohistochemistry, and in MCF-7 breast cancer cells by immunofluorescence and Western blot analysis. Considerable expression of key circadian genes, PERIOD 2, CLOCK, TIMELESS, CRYPTOCHROME 1, and CRYPTOCHROME 2 was also seen in all breast cancer cell lines and all patients' breast cancer tissues. These studies indicate that genes for PDE6 and control of circadian rhythm are expressed in human breast cancer cells and tissues and may play a role in transducing the effects of light on breast cancer.
\end{abstract}

Keywords: Breast cancer; Cyclic nucleotide phosphodiesterase; PDE6; Light; Circadian clock genes; cGMP signaling

\section{Introduction}

Cyclic Nucleotide Phosphodiesterases (PDEs) are encoded by 21 different genes grouped into 11 gene families based on sequence similarity, mode of regulation, and specificity for cAMP or cGMP as substrate (Francis, et al. 2011; Lerner and Epstein 2006). There is considerable interest in PDEs owing to studies showing them to be excellent candidate targets for treating a wide range of illnesses including hematological malignancies, osteoporosis and inflammatory and autoimmune diseases (Epstein 2012; Francis, et al. 2011; Lerner and Epstein 2006; Vang, et al. 2010). Catalytic subunits of PDE6, a cGMP-specific PDE, were thought to be photoreceptorspecific, localized exclusively to the outer segment of rods and cones in the eye, where they are crucial for the

\footnotetext{
*Correspondence: epstein@nso1.uchc.edu

'Departments of Cell Biology, University of Connecticut Health Center, 263 Farmington Ave, Farmington, CT 06030-3505, USA

Full list of author information is available at the end of the article
}

transduction of light (Stryer 1986; Zhang and Cote 2005). The rod outer segment (ROS) is a dual membrane system composed of about 2000 disks surrounded by a physically separate plasma membrane. The disks contain rhodopsin, PDE6 and transducin. The plasma membrane contains a cGMP-gated sodium channel. In the dark, the ROS contains an unusally high concentration of cGMP $(\approx 70 \mu \mathrm{M})$, which activates the sodium channel and depolarizes the membrane. When light impinges on rhodopsin on the disks, it photoisomerizes its chromophore, which in turn activates the GTP-binding protein, transducin, which activates the catalytic activity of PDE6 by dissociating its inhibitory $\gamma$ subunits. PDE6 then very rapidly reduces the cGMP concentration leading to inactivation of the sodium channels and hyperpolarization of the plasma membrane which is conveyed to the synapse at the other end of the rod and communicated to other cells of the retina (Stryer 1986; Zhang and Cote 2005). In the human rod, PDE6 is composed of two large $(\approx 99 \mathrm{kDa})$ catalytic subunits, $\alpha$ and

\section{实}


$\beta$, encoded by the PDE6A and PDE6B genes respectively, two small $(\approx 11 \mathrm{kDa})$ inhibitory $\gamma$ subunits encoded by PDE6G, and a small $(\approx 17 \mathrm{kDa}) \delta$ regulatory subunit encoded by PDE6D. The human cone PDE6 contains two $\alpha$ ' catalytic subunits encoded by $P D E 6 C$, two inhibitory $\gamma$ subunits encoded by $P D E 6 H$, and a regulatory $\delta$ subunit encoded by PDE6D (Ionita and Pittler 2007). The PDE6Dencoded $\delta$ subunit (PDE6 $\delta$ ) is not specific to PDE6 in that it binds to other enzymes and is expressed in other tissues (Zhang, et al. 2004). Its function as part of the PDE6 enzyme is unclear, although it is generally found to be bound to the soluble fraction of PDE6 in retina extracts and may play a role in transport of PDE6 to the disks or its translocation to the plasma membrane (Cook, et al. 2001; Zhang, et al. 2007). PDE6 $\delta$ has also been shown to function as a cytosolic farnesyl-binding chaperone protein for ras, which facilitates ras trafficking and signaling (Chandra, et al. 2012). The $\gamma$ inhibitory subunit of PDE6 is also expressed in other tissues such as lung and kidney cells (Guo and Ruoho 2008; Tate, et al. 2002) and has been suggested to play a role in the activation of MAP kinase by epidermal growth factor signaling (Wan, et al. 2003). PDE6 catalytic activity has also been reported in chick pineal gland where it is believed to mediate the light induced inhibition of melatonin synthesis (Holthues and Vollrath 2004; Morin, et al. 2001). In contrast to humans, in chick, both in rods and pineal glands, the catalytic activity of PDE6 appears to be comprised of homodimers of two $P D E 6 B$-encoded $\beta$ subunits, with no evidence for the expression of $P D E 6 A$-encoded $\alpha$ subunits present in these chick tissues (Huang, et al. 2004; Morin, et al. 2001). Inasmuch as cGMP has been shown to regulate proliferation and apoptosis of breast cancer cells (Saravani, et al. 2012; Tinsley, et al. 2011), we examined breast cancer cells for the expression of PDE6 genes. In this paper we show significant expression of PDE6B, PDE6C, and PDE6D, in human breast cancer cell lines and patients' breast cancer tissues.

\section{Materials and methods Materials}

Breast cancer/uninvolved paired tissue array (catalog no. BRC481) was obtained from Pantomics (San Francisco, CA, USA). Tissues were classified as tumor or uninvolved based upon H\&E staining and immunohistochemistry using anti-cytokeratin antibody and staged according to the standard TNM classification by a certified physician. Human breast adenocarcinoma estrogen receptor-positive MCF-7 and T-47D, and estrogen receptor-negative MDAMB-231 and MDA-MB-435 cell lines were obtained from American Type Culture Collection (Manassas, VA, USA). Breast cancer tumor tissues for microarray analysis were obtained from the Neag Cancer Center of the University of Connecticut Health Center (UCHC) in a deidentified manner. All procedures involving human tissue were approved by the UCHC Institutional Review Board. PDE6 $\beta$ specific antibody (catalog no. NB120-5663) was from Novus Biologicals (Littleton, CO). Alexa Fluor 350 conjugated goat anti-rabbit IgG was from Invitrogen (Carlsbad, CA). Horseradish peroxidase conjugated goat anti-Rabbit IgG was from GE Healthcare (Piscataway, NJ).

\section{Cell culture}

Cell lines were maintained in DMEM medium supplemented with $10 \%$ fetal bovine serum, $2 \mathrm{mM} \mathrm{L-glu-}$ tamine, $100 \mathrm{U} / \mathrm{ml}$ penicillin and $100 \mu \mathrm{g} / \mathrm{ml}$ streptomycin, at $37^{\circ} \mathrm{C}$ in a humidified atmosphere of $95 \%$ air and $5 \% \mathrm{CO}_{2}$.

\section{Microarray}

Microarray analyses were performed with Illumina Ref8 bead chips according to the manufacturer's directions. Data analysis was performed with Illumina Gene Studio software. Gene array data for cell lines or tumor samples were treated as separate groups and normalized using rank-invariant normalization of raw data. Statistical significance of each value was determined based upon signal variance for multiple probes for each gene to assume appropriate mRNA expression.

\section{Western immunoblot analysis}

Western immunoblotting analysis was performed as described previously (Vang, et al. 2013). MB-231 and MCF-7 breast cancer cells were centrifuged at $300 \times \mathrm{g}$ for $5 \mathrm{~min}$, washed twice with ice-cold phosphate buffered saline (PBS), and lysed in RIPA buffer (50 mM Tri$\mathrm{HCl}, \mathrm{pH}$ 7.4, $150 \mathrm{mM} \mathrm{NaCl}, 1 \mathrm{mM}$ EDTA, 1\% NP-40, $0.25 \%$ Na-deoxycholate with 1:100 dilution Sigma protease inhibitor cocktail). Protein concentration was determined using a Micro BCA Protein Assay Kit (Pierce, Rockford, IL). Equal amounts of protein were loaded and run on $10 \%$ SDS-PAGE gels. Proteins were then transferred onto Immobilon-p Transfer Membrane (Millipore). Membranes were blocked with 5\% BSA in Tris-buffered saline (TBS) for $1 \mathrm{~h}$ at room temperature and probed with 1:200 dilution of PDE6 $\beta$ specific primary antibody (Novus Biologicals) overnight at $4{ }^{\circ} \mathrm{C}$, washed three times with TBS-T (TBS with $0.1 \%$ Tween 20) buffer, and incubated with horseradish peroxidase-conjugated secondary antibody (GE Healthcare) at 1:5000 dilution for $1 \mathrm{~h}$ at room temperature and then washed three more times. Proteins were visualized with SuperSignal West Femto Maximum Sensitivity Substrate (Pierce, Rockford, IL) using a Syngene G:Box with Genesnap BioImaging software. Staining with anti-GAPDH (glyceraldehyde-3-phosphate dehydrogenase) antibody (Abcam) was used for loading control and normalization. 


\section{Immunofluorescence}

MCF-7 and MDA-MB-231 cells were seeded on a slide cell chamber at $5 \times 10^{3}$ cells/well. After growth for $24 \mathrm{~h}$ the cells were washed 3 times with PBS, fixed in $4 \%$ paraformaldehyde in PBS for $10 \mathrm{~min}$ and washed with PBS 3 times. The fixed cells were blocked with 5\% BSA in PBS containing $0.2 \%$ Tween- 20 at room temperature for $2 \mathrm{~h}$, incubated with primary anti-PDE6 $\beta$ antibody (1:50) overnight at $4^{\circ} \mathrm{C}$, washed 3 times and incubated with Alexa Fluor conjugated secondary antibody (1:200) for $1 \mathrm{~h}$, washed 3 times in PBS, counterstained with 4,6diamidino-2-phenylindole (DAPI) (1:5000 in PBS) for 2-5 min, washed 3 times and examined by fluorescent microscopy.

\section{Immunohistochemistry}

Immunohistochemistry was performed on $4 \mu \mathrm{m}$ thick paraffin sections from 16 cases of invasive breast cancer with corresponding uninvolved tissue obtained from Pantomics using primary PDE6 $\beta$ antibody and detection with Vector ImmPRESS anti-rabbit Ig (peroxidase) polymer detection kit using $\mathrm{DAB}$ substrate according to the manufactuer's protocol (Vector Laboratories, Burlingame, CA, USA). Controls without addition of primary antibody were performed to assure signal specificity. Nuclei were counterstained using methyl green.

\section{Results}

\section{Expression of PDE6 mRNA in breast cancer cell lines}

Expression of the mRNA for PDE6 genes was examined in the human breast adenocarcinoma estrogen receptornegative cell lines, MB-231 and MB-435, and in the estrogen receptor-positive cell lines, T47D and MCF-7, by microarray analysis. Figure $1 \mathrm{~A}$ shows the expression of mRNA for PDE6 catalytic subunit genes, PDE6A, 6B, and $6 C$. PDE6B was highly and significantly expressed in MCF-7 cells and to a much smaller extent in T47D cells, but not in MB-231 and MB-453 cells. PDE6C was highly and significantly expressed in all four of these breast cancer cell lines. PDE6A was minimally expressed at a significant level only in MB-231 cells, and not in any of the other breast cancer cells. Figure $1 \mathrm{~B}$ shows the expression of mRNA for PDE6 regulatory subunit genes, PDE6D, 6G, and $6 H$. No significant expression of genes for the rod inhibitory subunit, PDE6G, or the cone inhibitory subunit, $P D E 6 H$, was seen in any of the cell lines examined. The regulatory subunit gene, PDE6D, was, however, highly expressed in all four breast cancer cell lines.

\section{Expression of PDE6 protein in breast cancer cell lines} Using antibody specific for PDE6 $\beta$, the expression of PDE6B protein was examined in MCF-7 and MB-231 cells both by immunofluorescence and Western immunoblot

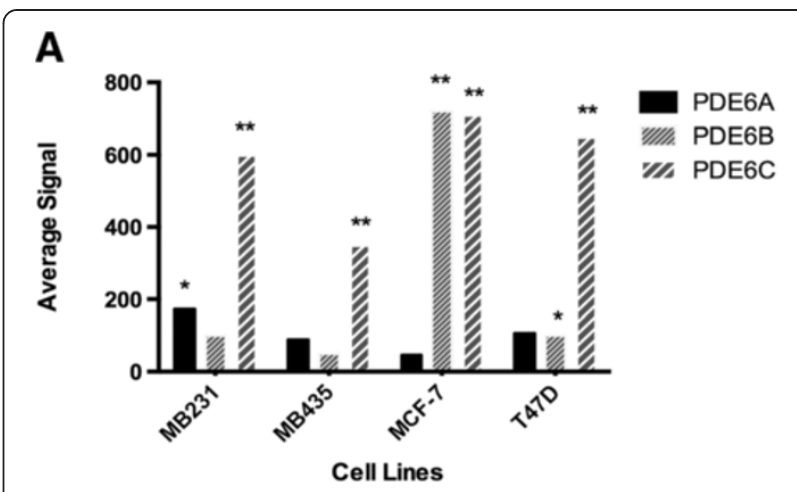

B

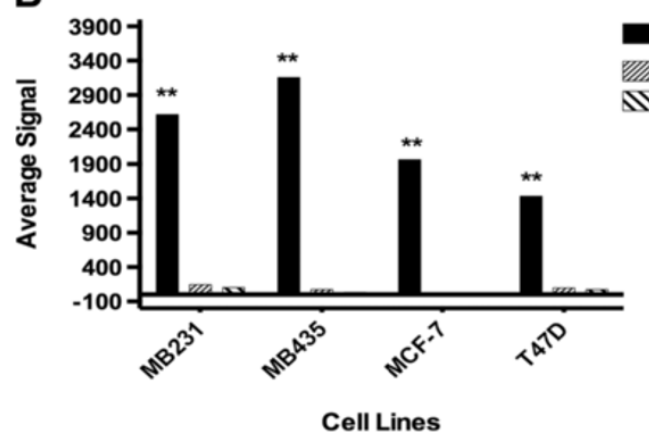

Figure 1 Expression of PDE6 mRNA in breast cancer cell lines. (A) Microarray analysis of PDE6 catalytic (PDE6A, 6B and 6C) subunit mRNA expression. (B) Microarray analysis of PDE6 regulatory (PDE6D) and inhibitory (PDE6G and $6 H$ ) subunit mRNA expression. ${ }^{* *} \mathrm{P}<0.01$ and ${ }^{*} \mathrm{P}<0.05$.

analysis. Consistent with PDE6B mRNA expression, as shown in Figure 2, by immunofluorescence, high expression of PDE6B protein was also seen in MCF-7 cells and the protein appeared to be expressed throughout the cell. Little expression of PDE6B protein was seen in MB-231 cells by immunofluorescence, again consistent with the mRNA expression. Also consistent with the PDE6B mRNA expression, as shown in Figure 3, PDE6 $\beta$ specific antibody recognized a band at $\approx 99 \mathrm{kDa}$ in MCF-7 cells by Western immunoblot analysis, but little expression of this band was seen in MB-231 cells.

\section{Microarray analysis of PDE6 mRNA in patients' breast cancer tissue}

PDE6 gene expression was analyzed by microarray analysis in breast tumor tissue from eight breast cancer patients. Similar to results with the breast cancer cell lines (Figure 1), in patients' tumor tissues, as shown in Figure 4A, only very minimal expression of PDE6A was seen, which only reached significance in two of the eight patients, patient numbers 4 and 5 . In contrast, $P D E 6 B$ and $P D E 6 C$ were significantly, and in many cases highly, expressed in all eight patients' tumor tissues. 


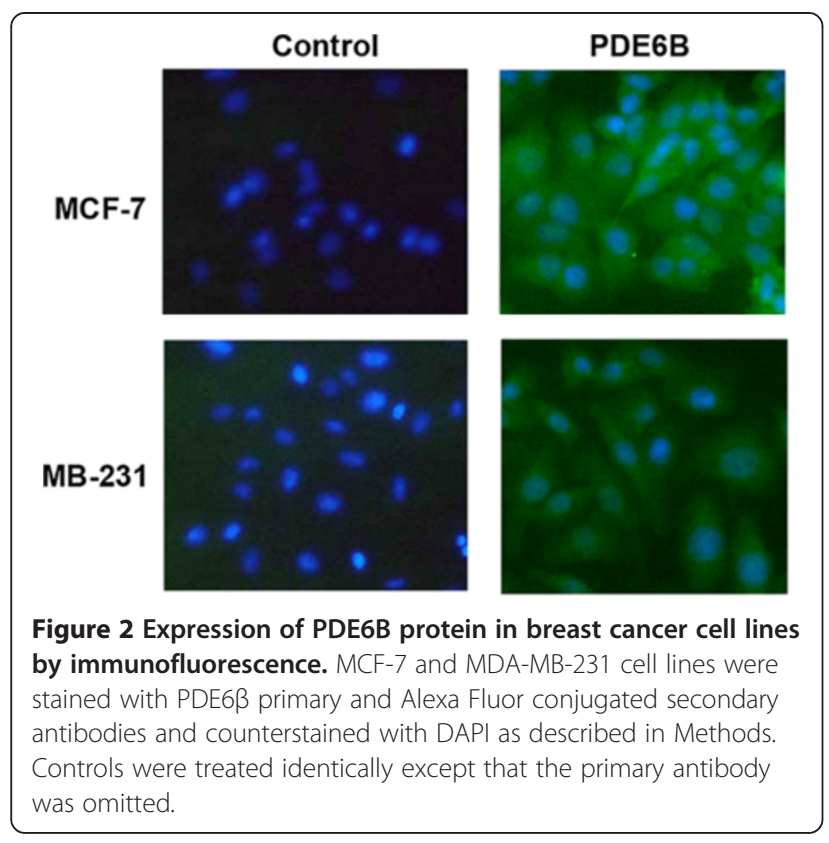

Examination of the expression of the PDE6 regulatory genes, shown in Figure 4B, also closely paralleled that seen in the breast cancer cell lines in that only very minimal expression for PDE6G was seen in any tissues, and no significant expression was seen for PDE6H at all, but considerable and significant expression was seen for PDE6D in all eight patients' breast tumor tissues. Estrogen receptor expression was also examined in these tissues to determine their estrogen receptor status. As shown in Figure 4C, significant expression of estrogen receptor $\alpha$ (ESR1) was seen in all patients' samples except for patient number 2, although the degree of expression varied considerably from patient to patient. Based on these data, there does not appear to be any obvious correlation between expression of PDE6 genes and estrogen receptor status.

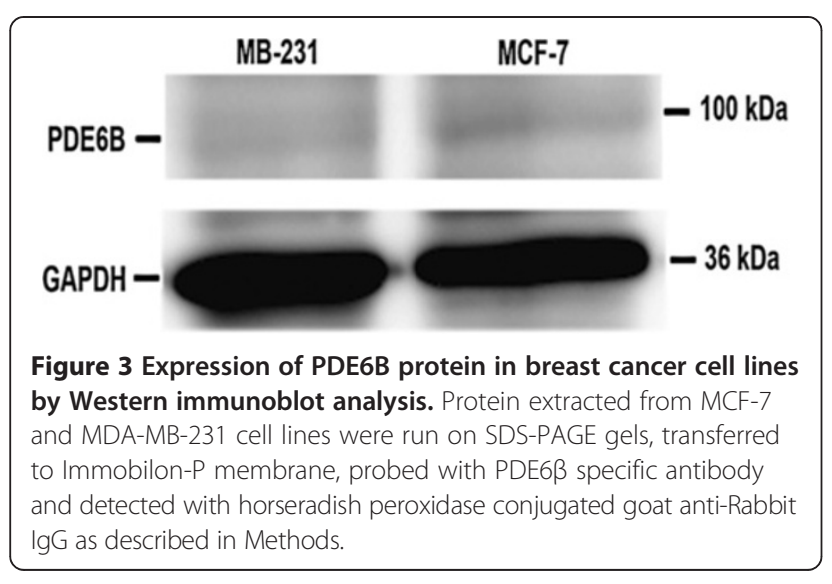

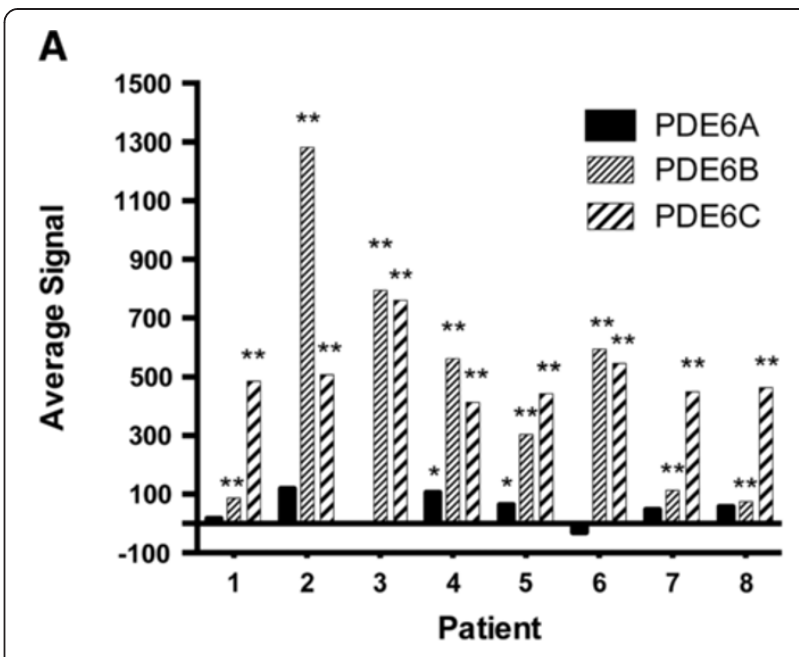

B
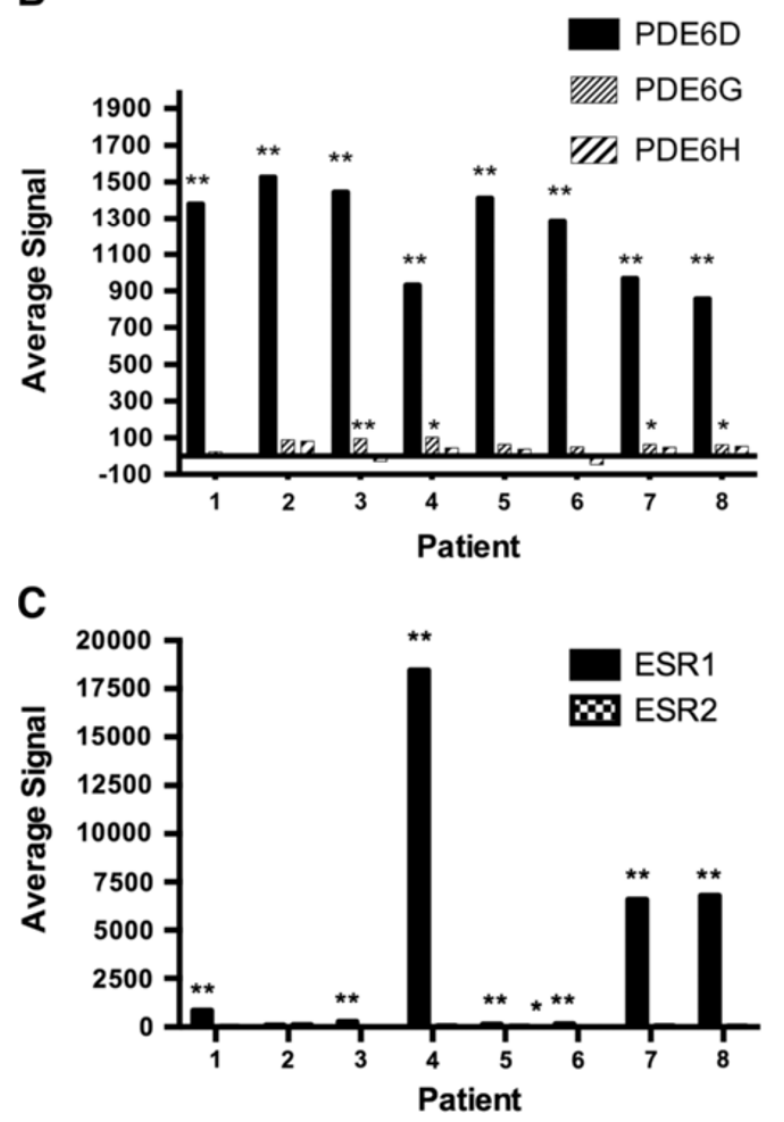

Figure 4 Expression of PDE6 and estrogen receptor mRNA in patients' breast cancer tissue. Breast cancer tumor tissues from eight patients were analyzed by lllumina microarray analysis. (A) Microarray analysis of PDE6 catalytic (PDE6A, $6 B$ and $6 C$ ) subunit mRNA expression. (B) Microarray analysis of PDE6 regulatory (PDE6D) and inhibitory (PDE6G and 6H) subunit mRNA expression. (C) Microarray analysis of estrogen receptor alpha mRNA expression. ${ }^{*} \mathrm{P}<0.01$ and ${ }^{*} \mathrm{P}<0.05$.

Expression of PDE6 protein in breast cancer tumors Using antibody specific for PDE6 $\beta$, the expression of PDE6B protein was examined in sixteen cases of invasive 
breast cancer and surrounding tissue by immunohistochemistry. Considerable expression of PDE6B protein was seen in all sixteen breast cancer tissue samples, regardless of what type of breast carcinoma they represented. The sixteen samples contained eleven cases of ductal carcinoma, three cases of lobular carcinoma, and two cases of poorly differentiated carcinoma. PDE6B expression in a representative example of each of these types of cancer is shown in Figure 5. Considerable PDE6B expression is seen in all of these, and expression is seen in the uninvolved tissue surrounding these tumors as well. In controls where primary PDE6 $\beta$ antibody was omitted, no labeling was seen at all (not shown). Although the tissue samples surrounding the tumors are classified as uninvolved, these do not necessarily represent normal breast tissue, since they are in proximity with the tumor and thus may already be in a precancerous state, exhibiting changes such as non-cancerous atypia or hyperplasia.

\section{Expression of phototransduction genes, wnt signaling} genes, and circadian clock genes in breast cancer cell lines and patients' tumors

Bazhin et al. showed that in addition to PDE6, other proteins in the phototransduction pathway, including rhodopsin, transducin, cyclic nucleotide gated (CNG) channels, guanylyl cyclase, rhodopsin kinase, recoverin and arrestin, are also expressed to varying degrees, although all to a lesser extent than PDE6, in melanoma cell lines and tissues, and they refer to these expressed genes as cancer-retina antigens (Bazhin, et al. 2007). It was also shown that PDE6 is expressed in murine F9 teratocarcinoma cells (Ahumada, et al. 2002) and that

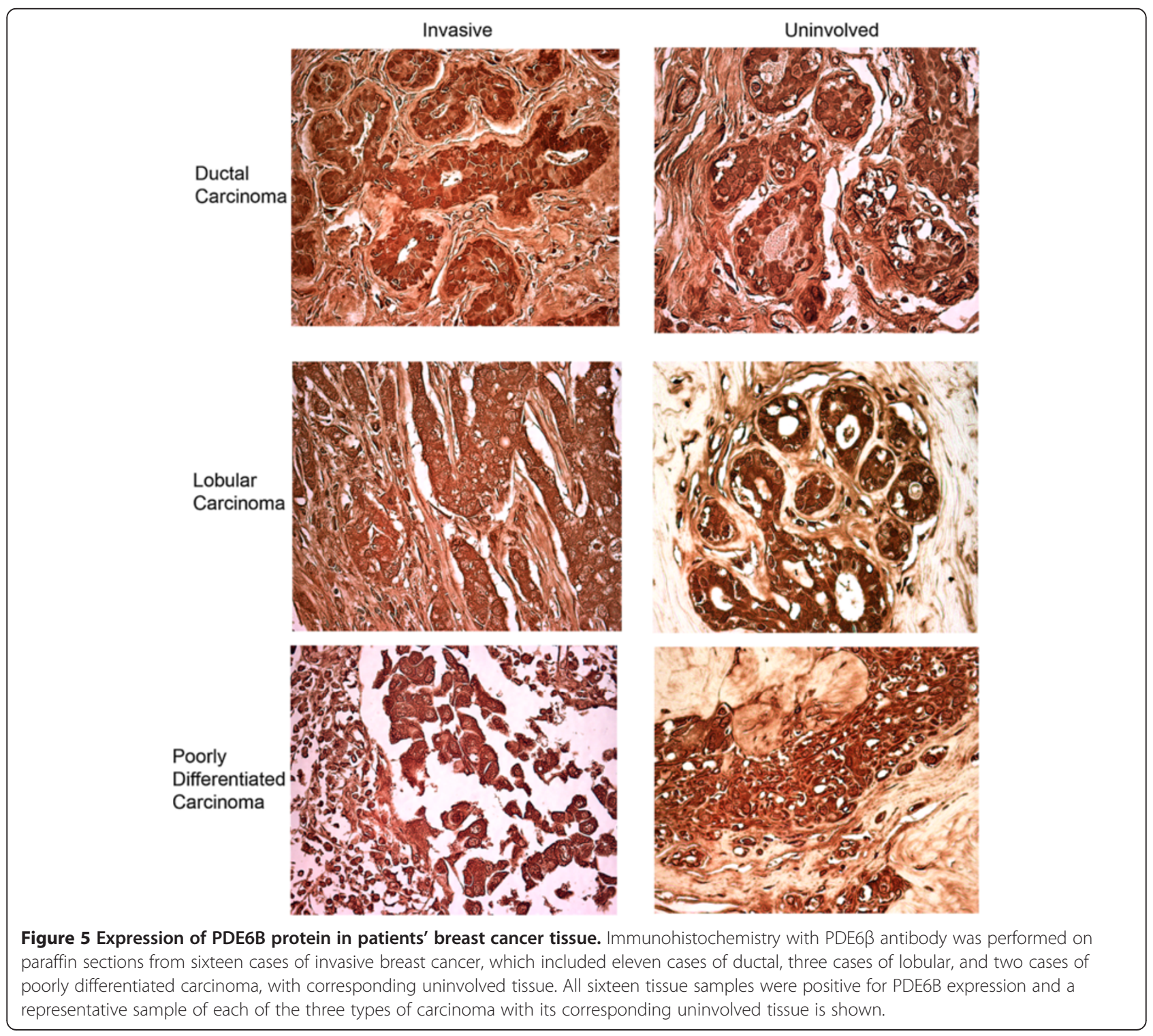


PDE6 in these cells as well as in melanoma cells (Bazhin, et al. 2010) is activated by the noncanonical Wnt signaling pathway through Wnt5a binding to Frizzled-2 receptors, leading to activation of transducin and subsequent activation of PDE6. The result of this is a reduced concentration of cGMP and increased concentration of $\mathrm{Ca}^{2+}$. Additional studies have shown that expression of key circadian clock genes are under the control of cGMP (Golombek, et al. 2004; Oster, et al. 2003; Plano, et al. 2012), and that disruption of the normal expression of these genes can result in the development of cancers, including breast cancer (Fu, et al. 2011; Fu and Lee 2003; Gery and Koeffler 2010; Hoffman et al. 2010a,b). For these reasons, we also examined the expression of other phototransduction pathway genes, Wnt signaling genes, and circadian genes in breast cancer cells and tissues. As shown in Table 1, examination of phototransduction genes in breast cancer cells and tissues reveals highly significant expression $(\mathrm{p}<0.01)$ of various isoforms of transducin, in addition to PDE6, but only minimal and sporadic expression of any of the other genes in the phototransduction pathway. Significant expression of WNT5A was observed in all of the patients' breast cancer tissues and in the MB-435 and MB-231 cells, but not in the MCF-7 and T47D cells. FRIZZLED-2 (FZD2) was significantly expressed in all breast cancer cell lines and tissues examined. The key circadian genes, PERIOD 2 (PER2 variant 2), CLOCK, TIMELESS, CRYPTOCHROME 1 (CRY1) and CRYPTOCHROME 2 (CRY2) were all also significantly expressed in all breast cancer cell lines and all patients' breast cancer tissues examined.

\section{Discussion}

These studies demonstrate that PDE6, formerly thought to be photoreceptor-specific, is expressed in breast cancer cells and tissues both at the mRNA and protein level. In contrast, microarray analysis of PDE6 in completely normal tissue, using a murine system, shows PDE6 expression to be restricted to photoreceptor tissue, with no evidence at all of any PDE6 expression in normal breast epithelium (Laule, et al. 2006). Several other studies have also detected expression of PDE6 in non-photoreceptor tissues; specifically, in murine F9 embryonic teratocarcinoma cells, in melanoma cells, and in human lung tissue (Ahumada, et al. 2002; Bazhin, et al. 2010; Nikolova, et al. 2010). In F9 teratocarcinoma cells PDE6 is activated by Wnt5a-Frizzled-2 signaling acting through transducin, which is also expressed in these cells, and inhibition of PDE6 with isobutylmethylxanthine, dipyridamole or zaprinast inhibits the formation of primitive endoderm induced by retinoic acid in these cells, suggesting a role for PDE6 in early embryonic development (Ahumada, et al. 2002). PDE6 as well as all the other components of the visual phototransduction pathway were found to be expressed both in normal melanocytes and melanoma cells at the mRNA level, but only in melanoma cells at the protein level (Bazhin, et al. 2007). Some melanoma cell lines expressed Wnt5a and Frizzled-2, and in these cell lines Wnt5a stimulated PDE6 activity, suggesting that in melanoma, PDE6 may be activated either by light impinging on rhodopsin, which is expressed in these cells, or by Wnt5a acting through Frizzled-2 and transducin (Bazhin, et al. 2010). A functional role for PDE6 in melanoma cells is still not known. PDE6 catalytic subunit mRNA and protein were found to be expressed in both normal and fibrotic human lung tissue, and at comparable levels, but expression of the PDE6D regulatory and PDE6G/H inhibitory subunits were significantly reduced in fibrotic lung tissue. Overexpression or suppression of PDE6D expression led to changes in cGMP levels, rate of proliferation, and state of ERK phosphorylation, suggesting that alterations in PDE6D expression and its consequent effects on PDE6 activity may be a causative factor for idiopathic pulmonary fibrosis (Nikolova, et al. 2010).

Considerable epidemiologic evidence has been amassed over the past 25 years demonstrating an association between increased exposure to LAN and increased rates of breast cancer (Flynn-Evans, et al. 2009; Kloog, et al. 2010; Stevens 2009a,b). Specific evidence for this includes increased incidence of breast cancer among women who work non-day shifts, lower incidence of breast cancer among totally blind women, an inverse relationship between breast cancer incidence and sleep duration, and a correlation between increased incidence of breast cancer and population LAN levels worldwide. This epidemiological evidence led the International Agency for Research on Cancer to classify shift work as a probable human carcinogen (Straif, et al. 2007). The molecular basis for effects of LAN on breast cancer are unknown, but inasmuch as the synthesis and secretion of melatonin from the pineal gland at night is very sensitive to suppression by LAN (Vanecek 1998), specifically only blue light in the wavelength range of 450-480 nm (Sanchez-Barcelo, et al. 2012), the general thinking has been that the reduced melatonin may be permissive for increased proliferation of breast epithelial cells and may thus play a role in the increased incidence of breast cancer (Sanchez-Barcelo, et al. 2012). Attention has also focused recently on the possibility that LAN exposure may affect circadian rythym through altering the expression of circadian genes and that this disruption of the circadian rhthym contributes to breast cancer development (Gery and Koeffler 2010; Savvidis and Koutsilieris 2012; Stevens 2009a, b). The body's circadian rythym is normally regulated by the expression of circadian genes in a master pacemaker in the suprachiasmatic nucleus of the hypothalamus that signals to oscillators in peripheral tissues (Savvidis and Koutsilieris 2012). As shown in this paper (Table 1), as 
Table 1 Expression of phototransduction pathways genes, Wnt genes, and Circadian rhythm genes

\begin{tabular}{|c|c|c|c|c|c|c|c|c|c|c|c|c|c|}
\hline & & \multicolumn{4}{|c|}{ Breast cancer cell lines (Average signal) } & \multicolumn{8}{|c|}{ Patients' breast cancer tissues (1-8) (Average signal) } \\
\hline & & MCF-7 & T47D & MB-435 & MB-231 & 1 & 2 & 3 & 4 & 5 & 6 & 7 & 8 \\
\hline \multicolumn{14}{|c|}{ Phototransduction genes } \\
\hline $\mathrm{RHO}$ & Rhodopsin & -45 & 27 & 31 & 87 & -43 & 40 & -63 & 14 & -45 & -90 & 13 & -1 \\
\hline GRK1 & Rhodopsin kinase & 4.25 & 102 & 70 & 133.9 & & & & & & & & \\
\hline GNAT1 variant 1 & Rod transducin alpha subunit & 0 & 77 & 69 & 133 & 8 & 85 & -12 & 54 & 31 & $4^{*}$ & 36 & 46 \\
\hline GNAT1 variant 2 & Rod transducin alpha subunit & 73 & $131^{*}$ & 90 & 124 & $54^{*}$ & 108 & $47^{* *}$ & 63 & $60^{* *}$ & -7 & $75^{*}$ & 59 \\
\hline GNAT2 & Cone transducin alpha subunit & 27 & 93 & 83 & $248^{* *}$ & 23 & $172^{* *}$ & -13 & 26 & $84^{* *}$ & -29 & 47 & 40 \\
\hline GNAZ & Cone transducin alpha subunit & $199 * *$ & 84 & $204^{* *}$ & 118 & $139^{*}$ & $132^{* *}$ & $131^{* *}$ & $80^{* *}$ & $255^{* *}$ & $8^{*}$ & $250^{* *}$ & 301 \\
\hline GNB1 & Transducin beta subunit & $22340^{* *}$ & $14936^{* *}$ & $14239^{* *}$ & $17968^{* *}$ & $20122^{* *}$ & $20994^{* *}$ & $17661^{* *}$ & $15477^{* *}$ & $21669^{* *}$ & $19486^{* *}$ & $20140^{* *}$ & $17137^{* *}$ \\
\hline GNB1L & Transducin beta subunit & $925^{* *}$ & $265^{* *}$ & $1160^{* *}$ & $1352^{* *}$ & $607^{* *}$ & $900^{* *}$ & $1030^{* *}$ & $261^{* *}$ & $295^{* *}$ & $749^{* *}$ & $270^{* *}$ & $343^{* *}$ \\
\hline GNB2 & Transducin beta subunit & $2968^{* *}$ & $675^{* *}$ & $1208^{* *}$ & $741^{* *}$ & $1456^{* *}$ & $691^{* *}$ & $1171^{* *}$ & $773^{* *}$ & $3845^{* *}$ & $1147^{* *}$ & $1066^{* *}$ & $1038^{* *}$ \\
\hline GNG2L & Transducin beta subunit & $69029^{* *}$ & $73280^{* *}$ & $43084^{* *}$ & $56176^{* *}$ & $62765^{* *}$ & $50370^{* *}$ & $70951^{* *}$ & $65617^{* *}$ & $74326^{* *}$ & $62703^{* *}$ & $59073^{* *}$ & $25580^{* *}$ \\
\hline GNB3 & Transducin beta subunit & $87^{*}$ & 95 & $136^{* *}$ & 118 & $111^{*}$ & $117^{*}$ & $50^{* *}$ & $179^{* *}$ & $126^{* *}$ & $23^{* *}$ & $76^{* *}$ & 96 \\
\hline GNB4 & Transducin beta subunit & 29 & $2157^{* *}$ & $831^{* *}$ & $1250^{* *}$ & $229^{* *}$ & $204^{* *}$ & $687^{* *}$ & $186^{* *}$ & $288^{* *}$ & $702^{* *}$ & $565^{* *}$ & 591 \\
\hline GNB5 variant 1 & Transducin beta subunit & 37 & 58 & $374^{* *}$ & $217^{* *}$ & $62^{* *}$ & 85 & $58^{* *}$ & 61 & $64^{* *}$ & $17^{* *}$ & 69 & 58 \\
\hline GNB5 variant 2 & Transducin beta subunit & -7 & 54 & 31 & 106 & 19 & 73 & -29 & 26 & 13 & -61 & 7 & 41 \\
\hline GNGT1 & Transducin gamma subunit & 60 & 102 & 63 & 113 & 17 & 89 & -24 & 63 & 25 & -33 & 40 & 31 \\
\hline GNGT2 & Transducin gamma subunit & -60 & 64 & 31 & 68 & 7 & 115 & $183^{* *}$ & 74 & 15 & $93^{* *}$ & 41 & 38 \\
\hline SAG & Arrestin & 1 & 85 & 67 & 107 & 33 & 99 & -44 & $107^{* *}$ & -1 & $14^{* *}$ & 56 & 51 \\
\hline RLV1 & Recoverin & -25 & 49 & 59 & 77 & -21 & 63 & 7 & 60 & 32 & -26 & 19 & 23 \\
\hline CNGA1 & CNG channel alpha subunit & 9 & 64 & 45 & 253 & 16 & 53 & $137^{* *}$ & 10 & $139^{* *}$ & -50 & 30 & 15 \\
\hline CNGA2 & CNG channel alpha subunit & 3 & 76 & 65 & 97 & 4 & 71 & -42 & 41 & 31 & -41 & 49 & 33 \\
\hline CNGA3 & CNG channel alpha subunit & -42 & 5 & 41 & 80 & -29 & 66 & -64 & 70 & -30 & -83 & $131^{* *}$ & $145^{* *}$ \\
\hline CNGB1 & CNG channel beta subunit & 13 & 23 & 27 & 81 & 6 & 74 & -34 & 19 & -7 & -35 & 15 & 17 \\
\hline CNGB3 & CNG channel beta subunit & 14 & 43 & 44 & 95 & 10 & 93 & -51 & 53 & -18 & -57 & 37 & 13 \\
\hline \multicolumn{14}{|l|}{ Wnt genes } \\
\hline WNT5A & Wnt & -31 & 10 & $293^{* *}$ & 113 & $915^{* *}$ & $670^{* *}$ & $84^{* *}$ & $490^{* *}$ & $775^{* *}$ & $266^{* *}$ & $195^{* *}$ & $267^{* *}$ \\
\hline FZD2 & Frizzled-2 & $864^{* *}$ & $1740^{* *}$ & $1828^{* *}$ & $4896^{* *}$ & $1213^{* *}$ & $220^{* *}$ & $1045^{* *}$ & $1576^{* *}$ & $1088^{* *}$ & $620^{* *}$ & $1176^{* *}$ & $1186^{* *}$ \\
\hline \multicolumn{14}{|c|}{ Circadian rhythm genes } \\
\hline PER1 & Period 1 & -25 & 69 & 53 & 80 & 32 & 100 & -23 & 64 & 25 & -1 & 62 & $102^{* *}$ \\
\hline PER2 variant1 & Period 2 & 7 & 56 & 59 & 93 & -6 & 72 & -31 & 32 & 21 & -48 & 41 & 8 \\
\hline PER2 variant2 & Period 2 & $5176^{* *}$ & $2856^{* *}$ & $1169^{* *}$ & $846^{* *}$ & $3847^{* *}$ & $2745^{* *}$ & $2693^{* *}$ & $3234^{* *}$ & $4415^{* *}$ & $3693^{* *}$ & $4735^{* *}$ & $4683^{* *}$ \\
\hline PER3 & Period 3 & 4 & 64 & 49 & 89 & 6 & 73 & -36 & 33 & 43 & -12 & $77^{*}$ & 47 \\
\hline
\end{tabular}


Table 1 Expression of phototransduction pathways genes, Wnt genes, and Circadian rhythm genes (Continued)

\begin{tabular}{|c|c|c|c|c|c|c|c|c|c|c|c|c|c|}
\hline CLOCK & Clock & $208^{* *}$ & $330^{* *}$ & $175^{* *}$ & $216^{* *}$ & $1001^{*}$ & $202^{*}$ & $364^{* *}$ & $352^{* *}$ & $575^{* *}$ & $353^{* *}$ & $468^{* *}$ & $411^{*}$ \\
\hline TIMELESS & Timeless & $5334^{* *}$ & $8868^{* *}$ & $3219^{* *}$ & $4254^{* *}$ & $2094^{* *}$ & $1527^{* *}$ & $1478^{* *}$ & $2427^{* *}$ & $1167^{* *}$ & $2119^{* *}$ & $1836^{* *}$ & $1603^{* *}$ \\
\hline CRY1 & Cryptochrome 1 & $1302^{* *}$ & $688^{*}$ & $682^{* *}$ & $2693^{* *}$ & $402^{* *}$ & $1071^{* *}$ & $474^{* *}$ & $707^{* *}$ & $326^{* *}$ & $1205^{* *}$ & $1052^{* *}$ & $1166^{* *}$ \\
\hline CRY2 & Cryptochrome 2 & $2862^{* *}$ & $1014^{* *}$ & $494^{* *}$ & $334^{* *}$ & $1058^{* *}$ & $908^{* *}$ & $1622^{* *}$ & $1611^{* *}$ & $2053^{* *}$ & $1604^{* *}$ & $1171^{* *}$ & $1078^{* *}$ \\
\hline
\end{tabular}


well as by others (Fu, et al. 2011; Hoffman et al. 2010a,b), circadian genes are expressed directly in breast cancer epithelial cells as well. Considerable evidence shows that expression of circadian genes are directly under the regulation of cGMP (Golombek, et al. 2004; Oster, et al. 2003; Plano, et al. 2012); thus, regulation of PDE6 in breast cancer cells by light or by Wnt5a signaling through Frizzled-2 and transducin, all of which we find expressed in breast cancer cells, could directly regulate the expression of circadian genes in these cells through alterations in cGMP levels. Although we find no evidence of rhodopsin in breast cancer cells to act as a light sensor, we do find high epression of CRY2 in these cells, and CRY2 can also act as a light sensor, absorbing light in its associated FAD molecule, intriguingly also specifically in the blue wavelength region of 450-480 nm (Hoang, et al. 2008), which may contribute to the activation of PDE6 in these cells, and the alteration in cGMP levels, leading to dysregulation of circadian genes, alterations in circadian rythyms, and the inducement or perpetuation of the growth of breast cancer cells. It is also noteworthy that increased cGMP levels have been shown to inhibit proliferation and induce apoptosis in breast cancer cell lines (Saravani, et al. 2012; Tinsley, et al. 2011) and it is thus possible that breast cancer cells have evolved to express PDE6 as a means to protect themselves against cGMP-mediated apoptosis to ensure their continued growth. While there is still much to be done to decipher the true function(s) for the expression of the light-activated PDE6 in breast cancer cells, this study nevertheless documents the expression of PDE6 in these cells, thereby uncovering a potential novel means by which exposure to LAN may result in breast cancer growth and development.

\section{Conclusions}

This paper demonstrates the novel finding of the expression of PDE6, the light sensitive PDE, previously thought to be photoreceptor specific, in breast cancer cell lines and patients' breast cancer tissues, at both the RNA and protein levels. This finding is discussed in the context of epidemiological evidence for exposure to artificial light at night as a risk factor for breast cancer and in relation to our further finding of the expression of circadian rhythm genes in these breast cancer tisssues.

\footnotetext{
Abbreviations

CNG: Cyclic nucleotide gated channels; CRY1: Cryptochrome 1; CRY2: Cryptochrome 2; DAPI: 4',6-diamidino-2-phenylindole; ESR: Estrogen receptor; FZD2: Frizzled-2; GAPDH: Glyceraldehyde-3-phosphate dehydrogenase; LAN: Artificial light at night; PBS: Phosphate buffered saline; PDE6: Phosphodiesterase 6; PER2: Period 2; ROS: Rod outer segment; TBS: Tris-buffered saline; UCHC: University of Connecticut Health Center.
}

\section{Competing interests}

The authors declare that they have no competing interests.

\section{Authors' contributions}

HD performed all the experiments in the paper with the exception of the microarray analyses, prepared the figures and performed the statistical analyses. KC contributed to the conception and design of the study, supplied the patients' breast cancer biopsies, and performed the micoarray analyses. SB contributed to the conception and design of the study and critically reviewed the manuscript. PE conceived the study, participated in its design and coordination and wrote the manuscript. All authors read and approved the final manuscript.

\section{Acknowledgements}

The authors acknowledge support for this work by grants from the Smart Family Foundation (PE, SB, KC), the Connecticut Breast Health Initiative Inc. $(\mathrm{PE}, \mathrm{SB}, \mathrm{KC})$, and the State of Connecticut Department of Public Health $(P E, S B, K C)$. This paper is dedicated to the memory of my sweet, beautiful, loving daughter, Serena Rae Epstein (March 22, 1984 - July 1, 2011), who has been and continues to be my inspiration for everything I do.

\section{Author details}

'Departments of Cell Biology, University of Connecticut Health Center, 263 Farmington Ave, Farmington, CT 06030-3505, USA. ${ }^{2}$ Immunology, University of Connecticut Health Center, Farmington, CT 06030, USA.

Received: 20 November 2013 Accepted: 20 November 2013

Published: 18 December 2013

\section{References}

Ahumada A, Slusarski DC, Liu X, Moon RT, Malbon CC, Wang HY (2002) Signaling of rat Frizzled-2 through phosphodiesterase and cyclic GMP. Science 298:2006-2010, doi:10.1126/science.1073776

Bazhin AV, Schadendorf D, Willner N, De Smet C, Heinzelmann A, Tikhomirova NK, Umansky V, Philippov PP, Eichmuller SB (2007) Photoreceptor proteins as cancer-retina antigens. Int J Cancer 120:1268-1276, doi:10.1002/ijc.22458

Bazhin AV, Tambor V, Dikov B, Philippov PP, Schadendorf D, Eichmuller SB (2010) CGMP-phosphodiesterase 6, transducin and Wnt5a/Frizzled-2-signaling control cGMP and $\mathrm{Ca}(2+)$ homeostasis in melanoma cells. Cell Mol Life Sci 67:817-828, doi:10.1007/s00018-009-0214-0

Chandra A, Grecco HE, Pisupati V, Perera D, Cassidy L, Skoulidis F, Ismail SA, Hedberg C, Hanzal-Bayer M, Venkitaraman AR, Wittinghofer A, Bastiaens PI (2012) The GDI-like solubilizing factor PDEdelta sustains the spatial organization and signalling of Ras family proteins. Nat Cell Biol 14:148-158, doi:10.1038/ncb2394

Cook TA, Ghomashchi F, Gelb MH, Florio SK, Beavo JA (2001) The delta subunit of type 6 phosphodiesterase reduces light-induced CGMP hydrolysis in rod outer segments. J Biol Chem 276:5248-5255, doi:10.1074/jbc.M004690200

Epstein PM (2012) Bone and the cAMP Signaling Pathway: Emerging Therapeutics. In: Bronner F, Farach-Carson MC, Roach T (eds) Bone Metabolic Functions and Modulators. Springer-Verlag, London, pp 271-287, doi:10.1007/978-1-4471-2745-1_16

Flynn-Evans EE, Stevens RG, Tabandeh H, Schernhammer ES, Lockley SW (2009) Total visual blindness is protective against breast cancer. Cancer Causes Control 20:1753-1756, doi:10.1007/s10552-009-9405-0

Francis SH, Blount MA, Corbin JD (2011) Mammalian cyclic nucleotide phosphodiesterases: molecular mechanisms and physiological functions. Physiol Rev 91:651-690, doi:10.1152/physrev.00030.2010

Fu L, Lee CC (2003) The circadian clock: pacemaker and tumour suppressor. Nat Rev Cancer 3:350-361, doi:10.1038/nrc1072

Fu A, Leaderer D, Zheng T, Hoffman AE, Stevens RG, Zhu Y (2011) Genetic and epigenetic associations of circadian gene TIMELESS and breast cancer risk. Mol Carcinog 51:923-929, doi:10.1002/mc.20862

Gery S, Koeffler HP (2010) Circadian rhythms and cancer. Cell Cycle 9:1097-1103, doi:10.4161/cc.9.6.11046

Golombek DA, Agostino PV, Plano SA, Ferreyra GA (2004) Signaling in the mammalian circadian clock: the NO/cGMP pathway. Neurochem Int 45:929-936, doi:10.1016/.neuint.2004.03.023

Guo LW, Ruoho AE (2008) The retinal cGMP phosphodiesterase gamma-subunit a chameleon. Curr Protein Pept Sci 9:611-625, doi:10.2174/ 138920308786733930

Hoang N, Schleicher E, Kacprzak S, Bouly JP, Picot M, Wu W, Berndt A, Wolf E, Bittl R, Ahmad M (2008) Human and Drosophila cryptochromes are light 
activated by flavin photoreduction in living cells. PLoS Biol 6:e160, doi:10.1371/journal.pbio.0060160

Hoffman AE, Yi CH, Zheng T, Stevens RG, Leaderer D, Zhang Y, Holford TR, Hansen J, Paulson J, Zhu Y (2010a) CLOCK in breast tumorigenesis: genetic, epigenetic, and transcriptional profiling analyses. Cancer Res 70:1459-1468, doi:10.1158/0008-5472.CAN-09-3798

Hoffman AE, Zheng T, Yi CH, Stevens RG, Ba Y, Zhang Y, Leaderer D, Holford T, Hansen J, Zhu Y (2010b) The core circadian gene Cryptochrome 2 influences breast cancer risk, possibly by mediating hormone signaling. Cancer Prev Res 3:539-548, doi:10.1158/1940-6207.CAPR-09-0127

Holthues H, Vollrath L (2004) The phototransduction cascade in the isolated chick pineal gland revisited. Brain Res 999:175-180, doi:10.1016/j. brainres.2003.11.059

Huang D, Hinds TR, Martinez SE, Doneanu C, Beavo JA (2004) Molecular determinants of cGMP binding to chicken cone photoreceptor phosphodiesterase. J Biol Chem 279:48143-48151, doi:10.1074/jbc.M404338200

Ionita MA, Pittler SJ (2007) Focus on molecules: rod CGMP phosphodiesterase type 6. Exp Eye Res 84:1-2, doi:10.1016/j.exer.2005.12.012

Kloog I, Stevens RG, Haim A, Portnov BA (2010) Nighttime light level co-distributes with breast cancer incidence worldwide. Cancer Causes Control 21:2059-2068, doi:10.1007/s10552-010-9624-4

Laule O, Hirsch-Hoffmann M, Hruz T, Gruissem W, Zimmermann P (2006) Web-based analysis of the mouse transcriptome using Genevestigator. BMC Bioinformatics 7:311, doi:10.1186/1471-2105-7-311

Lerner A, Epstein PM (2006) Cyclic nucleotide phosphodiesterases as targets for treatment of haematological malignancies. Biochem J 393:21-41, doi:10.1042/BJ20051368

Morin F, Lugnier C, Kameni J, Voisin P (2001) Expression and role of phosphodiesterase 6 in the chicken pineal gland. J Neurochem 78:88-99, doi:10.1046/j.1471-4159.2001.00407.x

Nikolova S, Guenther A, Savai R, Weissmann N, Ghofrani HA, Konigshoff M, Eickelberg O, Klepetko W, Voswinckel R, Seeger W, Grimminger F, Schermuly RT, Pullamsetti SS (2010) Phosphodiesterase 6 subunits are expressed and altered in idiopathic pulmonary fibrosis. Respir Res 11:146, doi:10.1186/1465-9921-11-146

Oster H, Werner C, Magnone MC, Mayser H, Feil R, Seeliger MW, Hofmann F, Albrecht U (2003) CGMP-dependent protein kinase II modulates mPer1 and mPer2 gene induction and influences phase shifts of the circadian clock. Curr Biol 13:725-733, doi:10.1016/50960-9822(03)00252-5

Plano SA, Agostino PV, de la Iglesia HO, Golombek DA (2012) cGMP-phosphodiesterase inhibition enhances photic responses and synchronization of the biological circadian clock in rodents. PLos ONE 7:e37121, doi:10.1371/journal.pone.0037121

Sanchez-Barcelo EJ, Mediavilla MD, Alonso-Gonzalez C, Rueda N (2012) Breast cancer therapy based on melatonin. Recent Pat Endocr Metab Immune Drug Discov 6:108-116, doi:10.2174/187221412800604581

Saravani R, Karami-Tehrani F, Hashemi M, Aghaei M, Edalat R (2012) Inhibition of phosphodiestrase 9 induces CGMP accumulation and apoptosis in human breast cancer cell lines, MCF-7 and MDA-MB-468. Cell Prolif 45:199-206, doi:10.1111/j.1365-2184.2012.00819.x

Savvidis C, Koutsilieris M (2012) Circadian rhythm disruption in cancer biology. Mol Med 18:1249-1260, doi:10.2119/molmed.2012.00077

Stevens RG (2009a) Electric light causes cancer? Surely you're joking, Mr. Stevens. Mutat Res 682:1-6, doi:10.1016/j.mrrev.2009.01.003

Stevens RG (2009b) Working against our endogenous circadian clock: Breast cancer and electric lighting in the modern world. Mutat Res 680:106-108, doi:10.1016/.mrrev.2009.01.003

Straif K, Baan R, Grosse Y, Secretan B, El Ghissassi F, Bouvard V, Altieri A, Benbrahim-Tallaa L, Cogliano V (2007) Carcinogenicity of shift-work, painting, and fire-fighting. Lancet Oncol 8:1065-1066, doi:10.1016/ S1470-2045(07)70373-X

Stryer L (1986) Cyclic GMP cascade of vision. Annu Rev Neurosci 9:87-119, doi:10.1146/annurev.ne.09.030186.000511

Tate RJ, Arshavsky VY, Pyne NJ (2002) The identification of the inhibitory gammasubunits of the type 6 retinal cyclic guanosine monophosphate phosphodiesterase in non-retinal tissues: differential processing of mRNA transcripts. Genomics 79:582-586, doi:10.1006/geno.2002.6740

Tinsley HN, Gary BD, Keeton AB, Lu W, Li Y, Piazza GA (2011) Inhibition of PDE5 by sulindac sulfide selectively induces apoptosis and attenuates oncogenic Wnt/beta-catenin-mediated transcription in human breast tumor cells. Cancer Prev Res 4:1275-1284, doi:10.1158/1940-6207.CAPR-11-0095
Vanecek J (1998) Cellular mechanisms of melatonin action. Physiol Rev 78:687-721 Vang AG, Ben-Sasson SZ, Dong H, Kream B, DeNinno MP, Claffey MM, Housley W, Clark RB, Epstein PM, Brocke S (2010) PDE8 regulates rapid Teff cell adhesion and proliferation independent of ICER. PLos ONE 5:e12011, doi:10.1371/ journal.pone.0012011

Vang AG, Housley W, Dong H, Basole C, Ben-Sasson SZ, Kream BE, Epstein PM, Clark RB, Brocke S (2013) Regulatory T cells and cAMP suppress effector T cells independently of PKA-CREM/ICER: a potential role for Epac. Biochem J 456:463-473, doi:10.1042/BJ20130064

Wan KF, Sambi BS, Tate R, Waters C, Pyne NJ (2003) The inhibitory gamma subunit of the type 6 retinal CGMP phosphodiesterase functions to link c-Src and G-protein-coupled receptor kinase 2 in a signaling unit that regulates p42/p44 mitogen-activated protein kinase by epidermal growth factor. J Biol Chem 278:18658-18663, doi:10.1074/jbc.M212103200

Zhang H, Li S, Doan T, Rieke F, Detwiler PB, Frederick JM, Baehr W (2007) Deletion of PrBP/delta impedes transport of GRK1 and PDE6 catalytic subunits to photoreceptor outer segments. Proc Natl Acad Sci USA 104:8857-8862, doi:10.1073/pnas.0701681104

Zhang H, Liu XH, Zhang K, Chen CK, Frederick JM, Prestwich GD, Baehr W (2004) Photoreceptor CGMP phosphodiesterase delta subunit (PDEdelta) functions as a prenyl-binding protein. J Biol Chem 279:407-413, doi:10.1074/jbc.M306559200

Zhang X, Cote RH (2005) CGMP signaling in vertebrate retinal photoreceptor cells. Front Biosci 10:1191-1204, doi:10.2741/1612

doi:10.1186/2193-1801-2-680

Cite this article as: Dong et al:: Expression of phosphodiesterase 6 (PDE6) in human breast cancer cells. SpringerPlus 2013 2:680.

\section{Submit your manuscript to a SpringerOpen ${ }^{\odot}$ journal and benefit from:}

- Convenient online submission

Rigorous peer review

- Immediate publication on acceptance

- Open access: articles freely available online

- High visibility within the field

- Retaining the copyright to your article

Submit your next manuscript at $\gg$ springeropen.com 